\title{
San Antonio de Areco, el santuario gaucho San Antonio de Areco, the gaucho sanctuary
}

\author{
Claudio Fabián Centocchi \\ Universidad de Buenos Aires, Argentina \\ cfcentocchi@yahoo.com
}

Recibido: 04-03-2017

Aceptado: 23-03-2017

\section{Resumen}

Este trabajo se propone describir algunas de las operaciones de producción de sentido que identifican a la marca destino San Antonio de Areco. San Antonio de Areco es una pequeña ciudad de la provincia de Buenos Aires (Argentina) que procura atraer al turismo a partir de posicionarse como el "Santuario de la Tradición". Para ello se vale, entre otros recursos, de la novela gauchesca Don Segundo Sombra, cuyo autor (Ricado Güiraldes) se inspiró en esas tierras. A través del empleo de herramientas que proporciona la semiótica, se analiza de qué modo se representa a esta localidad en un conjunto de paratextos y metadiscursos producidos por organizaciones periodísticas, gubernamentales y de servicios turísticos que se encuentran disponibles en internet. El estudio nos permite distinguir las fortalezas y debilidades que posee el dispositivo que rige en ese territorio, el cual expresa el triunfo de una controvertida posición ideológica.

Palabras clave: Don Segundo Sombra, marca, tiempo, tradición.

\begin{abstract}
This paper aims to describe some of the significant processes that identify the destination brand San Antonio de Areco. San Antonio de Areco is a small city in the province of Buenos Aires (Argentina) that seeks to attract tourism from positioning itself as the "Sanctuary of Tradition". To this end, it is worth, among other resources, of the gauchesca novel Don Segundo Sombra, whose author (Ricado Güiraldes) was inspired in those lands. Through the use of tools provided by the semiotics, it is analyzed how this locality is represented in a set of paratexts and metadiscourses produced by journalistic, governmental and tourist services organizations that are available on the Internet. The study allows us to distinguish the strengths and weaknesses that have the device that governs in that territory, which expresses the triumph of a controversial ideological position.
\end{abstract}

Key words: Don Segundo Sombra, Brand, Time, Tradition.

\section{Sumario}

1. Introducción: Propuesta y fundamentos | 2. Enfoque metodológico | 3. Disputas por la tradición: Hernández y/o Güiraldes | 4. Simbología de la marca | 5. Temporalidad I: El peso de lo simbólico | 6. Temporalidad II: Pasaje a la desaceleración | 7. Paradojas arequeras | 8. A modo de cierre | Referencias bibliográficas

\section{Cómo citar este artículo}

Centocchi, Claudo F. (2017): "San Antonio de Areco, el santuario gaucho", methaodos.revista de ciencias sociales, 5 (1): 130-141. http://dx.doi.org/10.17502/m.rcs.v5i1.141 


\section{Introducción: Propuesta general y fundamentos}

Las ciudades, al igual que los países, se esfuerzan hoy por gestionar su imagen a partir del concepto de marca ${ }^{1}$; requieren implementar acciones coordinadas diversas con el fin de seducir turistas e inversores externos, sin descuidar el vínculo de identificación con los residentes (Kavaratzis, 2004). Las tendencias homogeneizadoras globales avivan la competencia entre poblaciones por refinar y realzar sus respectivas identidades y posicionamientos.

Subsumido a lo anterior, las ciudades se instituyen para el sector específico del turismo como "marcas destino" que prometen al visitante una experiencia única gracias a la reunión de ciertos atributos tangibles e intangibles, funcionales y simbólicos.

La localidad argentina de San Antonio de Areco, ubicada a poco más de cien kilómetros al noroeste de la ciudad de Buenos Aires, no escapa a los mandatos actuales del city branding. Este trabajo se propone describir de qué modo esta pequeña ciudad de más de 20.000 habitantes $^{2}$ y sus alrededores se posicionan como el "Santuario de la Tradición". Una estrategia que excede en realidad -como se explicará en el siguiente apartado- la labor de las autoridades municipales. Tal posicionamiento la enfrenta con poblaciones de la pampa húmeda bonaerense (General Madariaga, Ayacucho, Uribelarrea), pero también con unidades espaciales menores como las estancias, por la pretensión de erigirse en la entidad que mejor expresa la cultura gauchesca.

De hecho, San Antonio de Areco se vale de un emblema que la diferencia de sus rivales: la figura de Don Segundo Sombra. Se ha apoderado del reconocido relato ficcional de Ricardo Güiraldes, publicado en 1926, en razón de que ese personaje célebre, que le da nombre a la novela, transita por la zona; recrea a un resero que trabajó en la estancia La Porteña, del padre del escritor, sita en los pagos arequeros ${ }^{3}$.

El texto cuenta el proceso de formación como gaucho de un joven huérfano bajo la guía de Sombra; un aprendizaje que concluye justo cuando descubre que es Fabio Cáceres, heredero de una significativa fortuna. Ese suceso lo lleva a convertirse en estanciero, acompañado por su maestro, hasta el momento en que este último tiene la necesidad de marcharse hacia la amplitud de la pampa y retomar su vida errante.

Considerada por numerosos críticos y estudiosos de la literatura como el mayor exponente de la novelística gauchesca (Pérez Blanco, 2003), fue transpuesta al cine con mínimas transformaciones narrativas, pero sin alcanzar reproducir la bella visualidad de sus descripciones impresionistas ${ }^{4}$.

Se abordará así un caso peculiar que se inscribe dentro de un movimiento mundial creciente en las últimas décadas, aunque todavía poco investigado, que procura activar procesos de visita a geografías "encantadas" por obra de la literatura, el cine, la televisión 5 .

Kim y Richardson (2003) plantean, en relación únicamente con el cine -extensible para la televisión y la literatura-, la incidencia que éste puede adquirir sobre la elección de un sitio vacacional al actuar sobre las motivaciones cognitivas y afectivas de viajeros indecisos. Conocer (más) un destino puede despertar sentimientos de seguridad y confort que abra paso a la confianza. O bien, acotadamente, se le puede atribuir a la fuerza que posee la ficción en términos de verosimilitud el acicate para desplazarse y recorrer territorios, aun cuando sean lejanos y conlleven sacrificios importantes (Tassara, 2011).

\footnotetext{
1 "La marca es un motor semiótico, su combustible está integrado por elementos tan dispares como nombres, colores, sonidos, conceptos, objetos, sueños, deseos, etc.; el resultado (si se ha hecho funcionar el motor adecuadamente) es un mundo ordenado, estructurado, interpretable y, en cierto sentido, atractivo" (Semprini, 1995: 47). Sintéticamente, es un grupo de significados en torno a una promesa.

2 El censo nacional de 2010 estableció 19.768 residentes (INDEC, 2010). Disponible en: http://www.indec.gov.ar/nivel4_default.asp?id_tema_1=2\&id_tema_2=41\&id_tema_3=135

${ }^{3}$ Hay un sólido acuerdo respecto a la filiación de Sombra con Don Segundo Ramírez. En un sitio web de promoción turística local, se sostiene a través de la palabra de un pintor influyente en Areco, Miguelángel Gasparini, que Güiraldes lo declaró al diario porteño Crítica en 1926. Ver http://www.sanantoniodeareco.com/carne-y-hueso-de-don-segundosombra

${ }^{4}$ El film Don Segundo Sombra se estrenó en 1969, con la dirección de Manuel Antín y la actuación protagónica de Adolfo Güiraldes, sobrino del autor.

${ }^{5}$ Sobre "literary tourism"se sugiere consultar Crang (2003) y Earl (2008).
} 
A fin de cuentas, el viajero siempre tiene modelada su mirada con anterioridad a la visita del lugar. La mirada "es construida y mantenida a través de una variedad de prácticas no turísticas, tales como el cine, la televisión, la literatura, revistas, grabaciones musicales y videos" (Urry, 2002: 3).

\section{Enfoque metodológico}

La oferta de una serie de atractivos que se asocian con lo gauchesco y, en particular, con Don Segundo Sombra no basta pues para aspirar a la obtención de preciados ingresos monetarios por el flujo turístico. Además de una adecuada infraestructura, es imprescindible un entramado de discursos acompañantes (MacCannell, 2003), paratextos y metadiscursos (Genette, 1989) que, de manera convergente, machaquen sobre la gracia que distingue al pago chico.

La marca San Antonio de Areco es la resultante de una pluralidad inmensa de discursos de todos los actores implicados (Semprini, 1995). No se constituye sin cesar sólo por las acciones comunicacionales del "polo de la producción" -dependencias de los gobiernos municipal, provincial-, sino también por las manifestaciones que la tienen por objeto de órganos periodísticos, agencias de turismo, visitantes, residentes, competidores, etc.

En consecuencia, para poder cumplir con la meta enunciada, tomaremos como unidades de análisis un conjunto variado de textos informativo-persuasivos de operadores influyentes, públicos y privados, que coadyuvan fuertemente en la configuración de la mirada de los viajeros (MacCannell, 2003; Urry, 2002). Nos centraremos en discursos generados por organizaciones gubernamentales, periodísticas y comerciales que surgen rápidamente a partir del uso del buscador de Google ${ }^{6}$.

La Web ha afectado sin duda los distintos sectores del funcionamiento social. Las prácticas relacionadas con el turismo se han modificado profundamente, en especial el modo en que el usuario se informa y concreta la adquisición de los servicios (Buhalis y Law, 2008). Además, Internet sirve como una vía de acceso a los medios tradicionales. Representa ya una ineludible vidriera.

La elección de ciertos actores en el ámbito de la Web permitirá describir, sin desfallecer, las principales reglas y condiciones a través de las cuales se sustenta esta marca destino. Por medio del herramental que proporciona la semiótica, se identificarán en esos productos de naturaleza híbrida las operaciones de investidura de sentido fundamentales que definen/ consolidan el posicionamiento comunicacional de Areco (Verón, 2004).

\section{Disputas por la tradición: Hernández y/o Güiraldes}

La palabra "tradición" remite al pasaje de ritos, costumbres, doctrinas de generación en generación (RAE, 2017) ${ }^{7}$. En Argentina se celebra cada 10 de noviembre debido al natalicio del poeta José Hernández, autor de El gaucho Martín Fierro y La vuelta de Martín Fierro, entre otras obras del género gauchesco.

El acuerdo de esa fecha en el Parlamento Nacional en 1975 marca el triunfo decisivo de la operación de asociar de modo reductor el acervo argentino a la cultura gauchesca ${ }^{8}$; un respaldo ideológico a las acciones que se vienen llevando a cabo en San Antonio de Areco en favor de erigir al gaucho como el gran símbolo patrio desde al menos el fallecimiento de Ricardo Güiraldes (en 1927) ${ }^{9}$.

\footnotetext{
${ }^{6} 202000$ resultados arrojó la búsqueda en enero de 2017 con las expresiones "San Antonio de Areco" + turismo. El corpus se desprende de una selección de ese nutrido listado. El algoritmo de Google privilegia las producciones locales o en el idioma de quien efectúa el rastreo (en este caso el castellano).

${ }^{7}$ Proviene del sustantivo latino "traditio" y del verbo "tradere", "entregar".

${ }^{8}$ Primero lo decretó la provincia de Buenos Aires mediante la Ley № 4756/39, promulgada el 18 de agosto de 1939. Posteriormente la Ley Nacional $\mathrm{N}^{\circ} 21154 / 75$, lo refrendó para todo el país.

${ }^{9}$ En el sitio oficial del municipio, se afirma que allí se efectúa "la celebración criolla más antigua del país como homenaje al hombre de campo y sus costumbres". Todo se inició con la "Fiesta de la Tradición" que "un grupo de vecinos y paisanos" organizaron en 1939. Ver http://www.areco.gob.ar/index.php/la-ciudad
} 
Sin embargo, el apoyo que suministraba esa Ley de la Nación era parcial ya que, junto al mencionado día de festejo, se estableció que el lugar donde nació Hernández, San Martín, enclavada en el conurbano bonaerense, sea la "Ciudad de la Tradición".

El criollismo es una cuestión de discrepancias resonantes en el campo literario/ intelectual nacional, donde entran a jugar criterios estéticos, de clase y políticos. El debate, intenso en el siglo pasado, pasa por dilucidar quién o quiénes transmiten en sus textos el "auténtico" criollismo, el que no se excede en la lengua y la temática, imperioso para que las nuevas generaciones puedan indagar su origen y espíritu (Altamirano y Sarlo, 1997).

La elección exclusiva de José Hernández por encima de cualquier otra personalidad en el Congreso no constituye un dato menor. Detrás del homenaje al autor del Martín Fierro se reivindica un pensamiento nacional-populista que destaca la épica verista, sin pretensión de vanguardia, contrario al poder ilustrado y burgués.

Esta situación se mantuvo prácticamente sin cambios hasta el año 2014. Sólo le otorgaron a San Antonio de Areco el premio consuelo de haber sido proclamada en 1984, por la Ley bonaerense $\mathrm{N}^{\circ} 10220$, "sede provincial permanente de la tradición". Algo es algo.

Si bien una norma de esa clase, meramente declarativa, no conduce a la masa de turistas a un determinado sitio, representa un aval útil. Ayuda en momentos en que se van instalando en la provincia de Buenos Aires variadas opciones que compiten de manera franca en rescatar y vivificar esta idiosincrasia rural; por ejemplo, la "Ruta de Juan Moreira", basada en seguir los pasos de un gaucho que como Don Segundo Sombra fue capturado por la literatura y el cine ${ }^{10}$.

Por ello, resulta meritorio el logro de la sanción de la Ley N² 27.105 el 17 de diciembre de 2014, donde San Antonio de Areco es designada "Capital Nacional de la Tradición". Sustituye así a San Martín, la cual paradójicamente simboliza hoy a nivel social la vida opuesta, la fabril. Esta decisión política confirma el reconocimiento a Hernández al no alterar la fecha de conmemoración, pero le brinda en simultáneo un espaldarazo a San Antonio de Areco y su proyecto marcario. También por ende indirectamente a Güiraldes, una figura controvertida por su linaje patricio y su sesgo cosmopolita, europeizante.

Ahora sí, este territorio puede sustentar con mayor seguridad los rótulos publicitarios que recalcan su devoción sin igual por el resguardo de la tradición. Mientras el tópico del gaucho como el arquetipo de la argentinidad, fogoneado por las elites en el imaginario desde hace un siglo, queda de nuevo legitimado. Esta vez, dada la distinción hacia ambos escritores, consiste en una entronización abierta que comprende tanto al actor combativo, matrero y forzado por la injusticia y la adversidad (Martín Fierro), como al actor hábil, dócil y trabajador, engranaje clave de la Argentina opulenta (Sombra y Cáceres). Se acogen así las acostumbradas facetas antitéticas del gaucho. Que cada lector dictamine, si simpatiza con el maniqueísmo, cuál es el héroe y cuál el villano.

\section{Simbología de la marca}

Una de las variables interdependientes estratégicas que construyen la promesa de una marca refiere a la presentación del signo primero y universal del nombre a través de una simbología razonada y coherente. Esta se compone de un conjunto de elementos gráficos de alta pregnancia: básicamente el logotipo, el isotipo y el cromatismo, que tienen como función expresar los valores esenciales de la marca (su identidad, personalidad y posicionamiento) (Wilensky, 2014).

Como parte de los esfuerzos por constituirse en un destino reconocible y atractivo, el municipio de San Antonio de Areco adoptó en los últimos años una simbología estable. Esa constelación sígnica procura conectarse con el "pasado" del lugar sin dejar de significar su "presente" y "futuro".

El imagotipo está compuesto por la denominación lingüística "San Antonio de Areco Municipio", acompañada por un ícono redondeado. La tipografía del logotipo es sin serif, mayúscula, de trazos uniformes, donde se enfatiza la palabra "Areco" mediante el grosor (uso de la variante "negrita"). Tal destaque impulsa a que el enunciatario abrevie el nombre, lleve a identificarla simplemente como "Areco",

\footnotetext{
${ }^{10}$ Consultar http://www.buenosaires.tur.ar/subproductos/loscaminosdemoreira
} 
pese a que existe en la propia provincia de Buenos Aires la localidad de Carmen de Areco, capital de un municipio vecino ${ }^{11}$.

La familia tipográfica que emplea el logo es la helvética regular, de amplia difusión desde hace más de cinco décadas, que se caracteriza por la sencillez y frialdad. Ese tipo de letra borra cualquier asociación tanto con la escritura a mano como con el mundo natural, lo que genera un sutil contrapunto con el signo que lo escolta.

En efecto, el componente que se ubica a la izquierda del nombre promueve de modo inmediato dos recorridos de sentido. Por un lado, si se impone el nivel de producción significante simbólico (Peirce, 1978), remite a la letra "a" minúscula cursiva, que condice con la inicial de Areco (la denominación que se intenta implantar) ${ }^{12}$. Por el otro lado, si consigue imperar el nivel de producción significante icónico (Peirce, 1978), el mismo elemento se asemeja a un estribo ${ }^{13}$ estilizado que se halla tendido.

Entre el logo y el pictograma se establece pues una combinación de la línea con la redondez; la rigidez con la blandura; la arbitrariedad con la motivación; la abstracción con la figuración; la actualidad con la tradicionalidad y la racionalidad con la emotividad (figura 1).

Figura 1. Imagotipo del Municipio de San Antonio de Areco

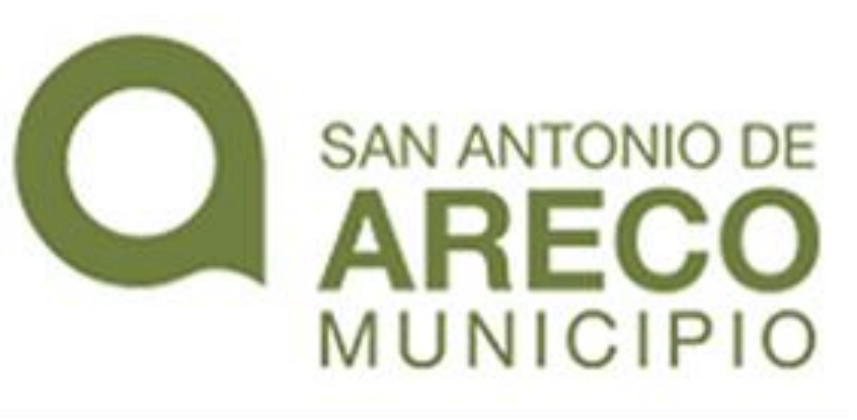

Fuente: http://www.areco.gob.ar/

El color verde oliva ayuda a otorgarle carga emocional. Mientras que el ícono se liga con un objeto identificatorio del gaucho, el cromatismo refuerza el ambiente de naturaleza. Connota asimismo tranquilidad, equilibrio, salud.

La tarjeta de presentación del municipio se completa con algunas frases breves que operan como eslóganes. Son sintagmas cristalizados, de uso recurrente de parte de organizaciones gubernamentales, periodísticas y de venta de servicios turísticos, que cooperan en la fijación del mensaje global del enunciador/ marca. "Capital nacional de la tradición"14, "Cuna de la tradición"15 y "Viví la tradición"16 constituyen los lemas más destacados. Los tres afirman que la tradición se encuentra allí. Las frases de corte referencial (Jakobson, 1988) "Capital nacional de la tradición" y "Cuna de la tradición" exaltan la oferta cultural arequera al considerarla como primera: ya sea en importancia -con el respaldo legal del Parlamento Nacional-, ya sea en términos de origen. La última frase, de predominio conativo (Jakobson, 1988), se dirige a seducir sin rodeos al visitante que busca tener una experiencia emocional inolvidable: la de vivir una cultura "otra", auténtica, ligada con las raíces argentinas.

San Antonio de Areco se inscribe, así, en uno de los tipos de turismo que se aleja de las variantes convencionales, el experiencial, en alza actualmente, el cual genera una puesta en valor de sus diferentes

\footnotetext{
${ }^{11}$ La distancia entre ambos centros urbanos, en línea recta, es apenas 35 kilómetros. Areco se llama el río que atraviesa la zona y bordea ambas ciudades.

12 Puede confundirse con la letra " $q$ ", minúscula de imprenta, ya que el trazo final concluye hacia abajo.

${ }^{13} \mathrm{El}$ estribo es una pieza que integra la silla de montar; le permite al jinete apoyar el pie.

${ }^{14}$ Consúltese por ejemplo http://www.areco.gob.ar/

${ }^{15}$ Ver por ejemplo http://www.caminopampa.com/\#the-tour

${ }^{16}$ Ver http://www.sanantoniodeareco.com/
} 
recursos del patrimonio histórico. Sigue una estrategia de construcción, promoción y comercialización que es desarrollada de manera oportuna en especial por zonas rurales de los cinco continentes. La simbología marcaria arequera brinda tímidas señales que expresan ese derrotero.

\section{Temporalidad I: El peso de lo simbólico}

La pampa húmeda, en especial, ha quedado impregnada por las profundas huellas discretas del gaucho. San Antonio de Areco rescata el costado "civilizado" de esa figura relevante de sus pagos, ya desaparecida como tal, a través de la puesta en escena de índices auténticos o fingidos que permiten reconstruir un específico modo de ser. La visita estándar que aconsejan todos los operadores comprende recorrer casonas bajas, pulperías, almacenes de ramos generales; transitar el empedrado a pie, en bicicleta o en carruaje. Entraña tomar contacto con las piezas de talentosos artesanos locales (talabarteros, plateros, ceramistas, sogueros y pintores). Implica disfrutar de prácticas como la doma, cuadreras, carrera de sortija, cabalgata, fogón criollo, guitarreada y mateada. Supone comer empanadas y asado de campo.

No se trata para el viajero de un habitual desplazamiento en el espacio; este destino propone a la vez trasladarse en el tiempo, a un pasado mítico que el pueblo entero se empeña en conservar por fuera, incluso de los diferentes museos y anticuarios. Con el peligro de que, si no hay límites, puede representar un corsé que justifique la desatención de las necesidades funcionales de la vida actual.

Promueve este proceso que privilegia la carga semántica (Barthes, 1993) la sanción de decretos como el que firmó el entonces presidente Carlos Menem el 10 de noviembre de 199917. La disposición 1305 declaró al casco urbano de San Antonio de Areco "Bien de Interés Histórico Nacional" y al Puente Viejo (figura 2), el Museo Ricardo Güiraldes, la Pulpería La Blanqueada, la Parroquia San Antonio, la Casa de la Intendencia Municipal y el Casco de la Estancia La Porteña como "Monumentos Históricos Nacionales" 18. Gaucholandia (Pérez Winter, 2013) deviene pues de la articulación de innumerables elementos que significan por contigüidad. Intentan probar al turista que, aquí, pese a su espíritu nómade, en estas construcciones y en estos parajes naturales, y manipulando estos objetos y desempeñando estas acciones que reproducen los descendientes legítimos o putativos, vivió este tipo social que aporta una fracción cara del ethos argentino.

"Al visitar San Antonio de Areco, podrás conocer el Museo y Parque Criollo Ricardo Güiraldes, los talleres de artesanos de primera calidad que posee, a la vez que tendrás una fuerte impronta de la tradición y costumbres del campo argentino, como así también testimonios vivientes de nuestra época colonial"19.

La historia de Don Segundo Sombra -al margen de la que tuvo su autor- refuerza considerablemente este artefacto persuasivo a través de dos operaciones de individualización que se complementan. La potente ficción narra hechos que llevan a cabo Fabio Cáceres y su mentor en inmuebles que aún perduran (por ejemplo, la Pulpería La Blanqueada y el Puente Viejo) (figura 2). A ese paquete promocional de atracciones se suman otras debido a que se vinculan con la biografía de Don Segundo Ramírez (por ejemplo, el Boliche de Bessonart) (figura 3):

"Con sus largos años de existencia, este almacén de comestibles y bebidas ha recibido entre sus paredes, hoy descascaradas por el tiempo, a infinidad de paisanos que llegaban hasta el pueblo a proveerse y realizar diligencias. Un habitual del lugar en aquel entonces era Don Segundo Ramírez, peón de la estancia de Güiraldes que le inspiraría el personaje de Don Segundo Sombra"20.

\footnotetext{
17 Justamente el Día de la tradición.

18 http://www.saij.gob.ar/1305-nacional-monumentos-historicos-nacionales-dn19990001305-1999-11-10/1234567890abc-503-1000-9991soterced

${ }^{19}$ https://www.welcomeargentina.com/sanantoniodeareco/historia.html

${ }^{20} \mathrm{http}: / /$ www.argentinaturismo.com.ar/san-antonio-de-areco/almacen-de-don-segundo-sombra-.html
} 
Esta red de variados elementos que operan metonímica/ sinecdóquicamente, gracias a los marcadores, resulta imprescindible para poder cumplir con la ambición de dispensar a la fachada de San Antonio de Areco ese halo de autenticidad que ya se ha perdido en las urbes (MacCannell, 2003; Amin y Thrift, 2002). Numerosos destinos que encarnan el llamado "turismo cultural" se valen actualmente de este tipo de estrategia ante la demanda creciente de nostalgia de los viajeros (Stewart, 1984).

Sin embargo, la escenificación que monta la localidad bonaerense parece entregar algo más. Los marcadores analizados no solo actúan de manera manifiesta en conectar a las vistas por contigüidad con la cultura gaucha (base indicial) sino que, a veces subrepticiamente, avanzan y lo realizan por vía metafórica (icónica). Ello sucede cuando impera la descripción de sitios rústicos, austeros, silenciosos y quedados. Como si esos engranajes hubiesen absorbido el temperamento del gaucho y se terminaran asimilando a él. Una impresión que se transmite con más naturalidad por medio de la fotografía que de la escritura (figuras 2 y 3). Un pestañeo mágico que logra incrementar el encanto del destino.

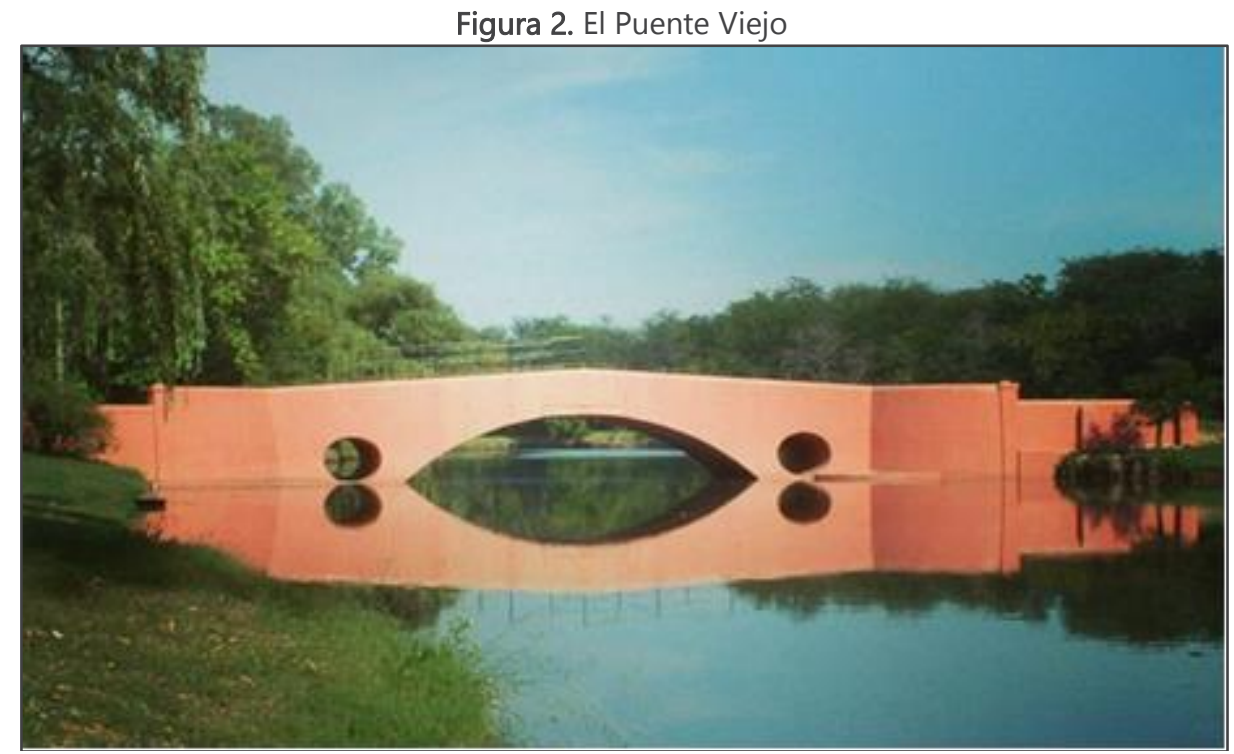

Fuente: http://www.sanantoniodeareco.com/el-puente-viejo

Figura 3. Boliche de Bessonart

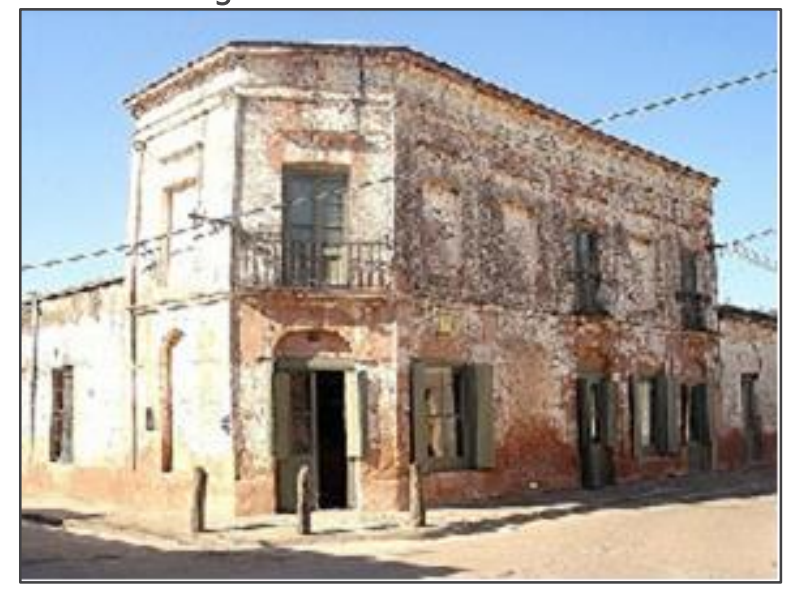

Fuente: http://www.viajarabuenosaires.com/?page=sanantoniodeareco.php 
La construcción mediática de San Antonio de Areco no se agota empero en esas dos variantes semióticas. Hay una última que se sustenta en las ya explicadas y que interviene cuando los paratextos concluyen que todos los rincones del poblado significan simbólicamente el "gauchismo"; ese estado del alma que representa, entre otros congéneres, a Don Segundo Sombra.

El arequero por antonomasia. La modalidad simbólica se orienta a generalizar. En este caso, pretende sostener en definitiva que Areco es la Tradición. Es el prototipo de un nítido proyecto ideológico.

"No es que un año atrás fuera difícil ver un carruaje en Areco, pero, aunque resulte curioso, sólo desde noviembre último está vigente la ordenanza que permite la circulación de tan criollo transporte. 'Si en Venecia pueden andar en góndola, acá podemos andar en carruaje', como proclamó un vecino en pleno debate. En Areco, se ve, la tradición es ley"21.

'Otro porteño radicado en Areco desde hace diez años es Patricio Santos Ortega, actual director de Turismo. 'La sociedad arequera es conservadora -dice-. La marca que dejó Ricardo Güiraldes es mucho más fuerte de lo que cualquiera de afuera puede interpretar. Al tema de la tradición lo sienten, lo viven y lo pelean. Por ejemplo, cuando arregla un poco su casa, la persona más sencilla, lo he visto, prefiere gastar unos pesos más y poner una puerta de madera, una moldura... Es un fenómeno sociológico muy interesante. Y en gran parte viene de ahí: del hito histórico que fue Don Segundo Sombra"22.

Siguiendo a Tassara (2011), es posible encontrar en la ficción cinematográfica ciudades que se configuran de manera simbólica, Metrópolis (Lang, 1927) y Los Angeles del año 2019 del film Blade Runner (R. Scott, 1982), que expresan respectivamente "la alegoría maquinista de von Harbour" y "la concepción decadente de futuro propia de cierta ciencia ficción" (p. 236) 23.

\section{Temporalidad II: Pasaje a la desaceleración}

La propuesta turística arequera estriba, como ya se planteó, en retrotraerse a un pasado estático e intacto. Implica abandonar el duro y ordinario presente para trasladarse a un ayer que, pese a su imprecisión, se asocia de inmediato con los mitos (Barthes, 1994) de "la magnificencia de la pampa" y "la Argentina próspera". Se le invita al viajero a realizar una "escapada" de un día, a lo sumo un fin de semana, para conocer el mejor "santuario gaucho" 24 . Un plan original para billeteras flacas que desean recuperarse de los vicios urbanos en compañía de la familia o de amigos.

Esta localidad ha capturado otra época, la cual lleva a ser experimentada cognitiva y emocionalmente bajo un flujo temporal ralentizado. La contemplación, la caminata, el paseo en bicicleta o a caballo imprime un ritmo saludable de apropiación de ese universo que se inclina a enaltecer lo rural.

"En plena pampa húmeda, el destino turístico es ideal para alejarse de los ruidos citadinos y sumergirse en las costumbres que persisten en el campo argentino"25

"(...) año tras año son cada vez más los turistas que eligen Areco para relajarse y disfrutar de la cultura gauchesca"26.

\footnotetext{
${ }^{21} \mathrm{http} / / /$ www.lanacion.com.ar/921720-la-tradicion-segun-san-antonio-de-areco

${ }^{22}$ http://www.lanacion.com.ar/921720-la-tradicion-segun-san-antonio-de-areco

${ }^{23}$ Los tres modos de producción de sentido que se caracterizan en este parágrafo proceden obviamente del desarrollo teórico de Peirce (1978). Pero también se corresponden con las reflexiones que efectúa Metz (1979) en relación con los procesos figurales en el cine.

${ }^{24} \mathrm{http}: / /$ www.buenosaires.tur.ar/localidades/sanantoniodeareco

${ }^{25} \mathrm{http}$ ///turismo.perfil.com/34521-asi-andan-los-gauchos-a-112-kilometros-de-buenos-aires/

${ }^{26}$ http://www.areco.gob.ar/index.php/turismo
} 
Las imágenes fotográficas son las que captan con mayor claridad y belleza este cambio en el transcurrir. La primacía de los paisajes campestres y el recorte de entidades inmóviles, solitarias, en pose, connotan ese sosiego (figura 4). Las proezas de los jinetes son las únicas estampas que lo ponen en cuestión.

Figura 4. Charla de arequeros

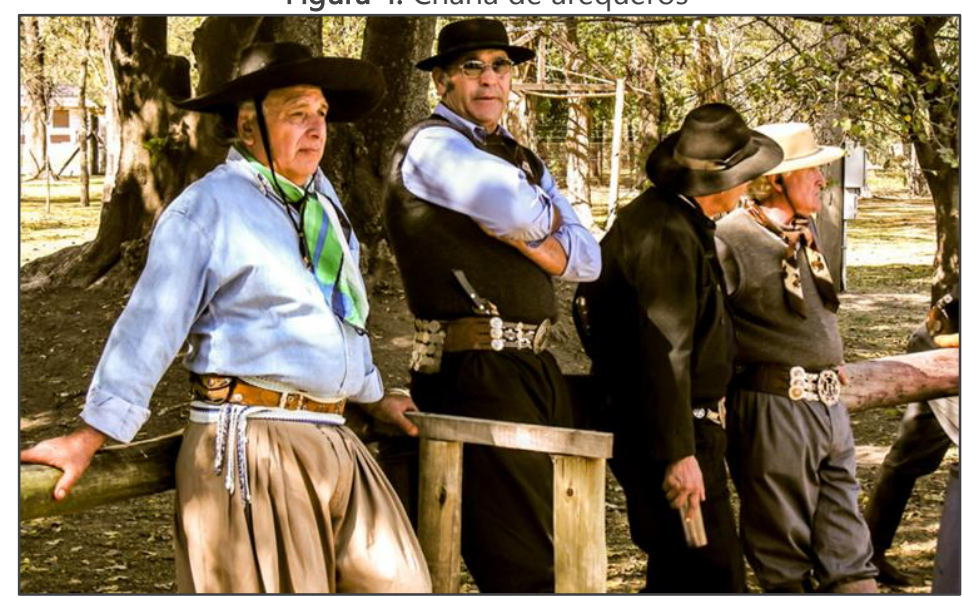

Fuente: https://www.welcomeargentina.com/sanantoniodeareco/citytour-areco.html

Ha surgido a fines de los años '90 dentro del "turismo cultural"/"turismo experiencial" una oferta distintiva que alienta precisamente la adopción de un ritmo más pausado en las vacaciones. San Antonio de Areco se encuadra en el "turismo slow", tributario de una tendencia filosófica global, que afecta variadas prácticas sociales (cuenta con una gran cantidad de adeptos en la alimentación, el trabajo en las empresas, etc). La ganancia para el visitante lentificado pasaría por lograr un bienestar psicológico, tomar un contacto más profundo con "la autenticidad y diferenciación locales, mantener comportamientos respetuosos con el medio ambiente y la cultura del destino y, cómo no, fortalecer las relaciones interculturales con las poblaciones anfitrionas" (Rivera Mateos, 2013: 205).

\section{Paradojas arequeras}

Los operadores suelen destacar de Areco, de modo manifiesto o indirecto, la vivencia de esos dos tiempos conjugados que identifican a la unión de una geografía (la pampa) con una etnia (el gaucho). Tiempos que se encarnan en entidades, prácticas y narraciones singulares -cuyo eje primordial es Don Segundo Sombra, que consiguen atraer más de 15000 turistas en un domingo soleado ${ }^{27}$.

La suerte de esta pequeña ciudad depende mucho de esa marea humana que empero aparece relegada en las referencias de las páginas web municipales de viajes y periodísticas, prácticamente, a una mención numérica y como telón de fondo en pocas fotografías. Ello contribuye a producir la imagen de un lugar puro, bucólico, no infectado por el presente al que numerosos excursionistas procuran escapar. El acierto en la estrategia comunicacional resultante estriba en centrarse en el otro, en lo extraño, para el peregrino, aunque constituya un disfraz.

Dicha modalidad constructiva exhibe, sin embargo, grietas. Los artículos periodísticos son los que más se encargan de atentar en contra de su cohesión, no tanto porque evidencien el paso transitorio del forastero sino porque, en su afán de informar de manera abierta y distantes al negocio fundamental, exponen verbalmente el lado cosmopolita y ordinario del poblado:

\footnotetext{
${ }^{27}$ https://www.pagina12.com.ar/diario/suplementos/turismo/9-3174-2015-09-24.html
} 


\begin{abstract}
"Andrés Ziperovich, director de Turismo local, precisa que hay 35 restaurantes. Si bien la carne domina el panorama, también hay opciones para el tapeo y el sushi, a los que se suman las clásicas pastas"28. "Jueves 1, 22:00-Bar El Mitre, Mitre y Alsina

VARIETÉ: Posta. Nuevas situaciones, nuevos actores y nuevos sketches entre sillas y mesitas. Y mezclados entre bandejas y camareras números de magia y circo. Espectáculo a la gorra.

Viernes 2, 23:00-Tumba'o, San Martín 383

JAZZ en Tumba'o. Manfred Schwarkopt y Hernán Urán en guitarras y Carolina Urán con voz, y una propuesta diferente pero no menos seductora en el Pago. Reservas: 02326-45-6296"29
\end{abstract}

La escenografía añosa y nativa queda enlodada, así, por la publicitaria existencia material de lo contemporáneo que responde a la globalización cultural. ¿Quién puede sorprenderse de que allí se ofrezca sushi, tapeo o un concierto de jazz si constituyen alternativas usuales de disfrute en cualquier rincón del planeta? Es ese presente absoluto que, a diferencia del ciclo que Areco intenta conservar, no se vincula con la cultura de un territorio sino con la cultura de un tiempo (Bauman, 1999). La cuestión radica en por qué se expresa sin disimulo su inevitable injerencia (incluso de parte de las autoridades del municipio).

Ese tipo de informaciones anticipa, sin duda, una estadía previsible, segura y versátil. Pero daña el ADN de la marca, aquello que motiva a los turistas a emprender el viaje con ánimo de alejarse de lo ya conocido y a entablar una interacción genuina con otra cultura. Pierde contundencia la declaración de que se trata de una "tierra de gauchos con mucha historia"30.

La restante contradicción que late en los discursos difusores de San Antonio de Areco afecta, en cambio, a la propuesta de "turismo slow". El terreno invita a ser recorrido con medios de locomoción que favorecen un estilo pausado, lo que permite abrigar el anhelo de una vivencia intensa de las diversas facetas que definen al buen gaucho. "El turista lento concede prioridad (...) a los aspectos cualitativos de la experiencia turística más a que los cuantitativos y desea pasar más tiempo en contacto con una localidad o microdestino" (Rivera Mateos, 2013: 205). Esto último es lo que precisamente se desestima en el caso analizado.

En efecto, no se ajusta con la filosofía slow el argumento de que bastan pocas horas de permanencia para poder experimentar con calidad un acervo nutrido. Las agencias de turismo ofertan exclusivamente tours que duran de uno a tres días:

'Los invitamos a vivir un día inmersos en la cultura gauchesca, rodeados del ambiente y naturaleza autóctona del campo argentino. Estamos comprometidos en brindar a nuestros visitantes la mas original y auténtica experiencia en 'Las Pampas de Argentina" ${ }^{31}$.

"2 Días en San Antonio de Areco con Estancia

También ofrecemos un paquete escapada de 2 días a San Antonio de Areco con alojamiento en Estancia. Visita guiada del casco histórico y museo Ricardo Güiraldes, almuerzo en el pueblo, y estancia. Incluye: traslado ida y vuelta desde Buenos Aires - Guías bilingües locales (inglés, francés, portugués) almuerzo completo con bebidas en el pueblo - alojamiento y pensión completa en estancia - todas las actividades de estancia"32.

La excursión es el formato indicado también por los textos periodísticos:

"El pueblo de infancia de Ricardo Güiraldes, que encontró en estas pampas inspiración para escribir Don Segundo Sombra, es un refugio de las tradiciones gauchas y un sitio pintoresco que alberga interesantes museos, ideal para disfrutar en los fines de semana de primavera" ${ }^{33}$.

\footnotetext{
${ }^{28}$ https://www.pagina12.com.ar/diario/suplementos/turismo/9-3174-2015-09-24.html

${ }^{29} \mathrm{http}: / /$ www.eldiariodeturismo.com.ar/2014/04/30/finde-extra-largo-en-san-antonio-de-areco/

${ }^{30}$ En http://www.areco.gob.ar/index.php/turismo

${ }^{31} \mathrm{http}: / /$ www.caminopampa.com/

$32 \mathrm{En} \mathrm{http://www.sanantoniodeareco.com/areco-tradicion.} \mathrm{Este} \mathrm{sitio} \mathrm{reproduce} \mathrm{las} \mathrm{propuestas} \mathrm{de} \mathrm{la} \mathrm{agencia} \mathrm{de} \mathrm{turismo}$ oficial Areco Tradición.

${ }^{33}$ https://www.pagina12.com.ar/diario/suplementos/turismo/9-3174-2015-09-24.html
} 


\section{A modo de cierre}

Los procesos de patrimonialización y turistificación han posibilitado que la marca San Antonio de Areco se erija actualmente como el gran "Santuario de la Tradición". Es gracias a un cúmulo de hechos heterogéneos de individuos e instituciones, donde los Güiraldes han sido actores protagónicos y desde el reconocimiento que recibió la novela, que este destino puede arrogarse de manera verosímil la representación de una identidad muy significativa para los argentinos (Pérez Winter, 2013), aunque solo recupere el perfil "noble" del gaucho e ignore aquel que, en contraposición, ensalza cierta literatura popular.

Lo lleva a cabo a pesar de que el personaje de Sombra, epítome de ese gaucho admirable, recorre la pampa sin querer afincarse. Salvo por esos tres años que se mantiene junto al súbito estanciero (Cáceres), nunca se dejó acorralar por los alambrados ni la inserción del país al mercado mundial. Sin embargo, el positivismo de San Antonio de Areco lo fija a su jurisdicción, amparándose en que esa geografía fue la que inspiró a su pluma creadora.

La marca destino se apropia del gaucho sin desechar el marco espacio-temporal que lo contuvo. Ello entraña la utilización del campo, así como la compleja exigencia de conservar un período borroso de la Historia, que ha decantado grosso modo como excepcional. La consigna es vivenciarlo en "slow motion". Al igual que Roma, Venecia o Carcassonne, la localidad bonaerense se somete a la significación (Barthes, 1993). Es un dispositivo (Agamben, 2006) que se orienta a defender (una versión sesgada, a la vez legitimada, de) la tradición ${ }^{34}$.

En esa red de elementos variados -bienes patrimoniales, prácticas, normas, etc.-, poseen un rol esencial los discursos elogiosos de operadores que influyen en la decisión de viajar y que moldean la mirada previa del visitante (MacCannell, 2003; Urry, 2002). Este trabajo posó su atención en ellos, distinguiendo algunas de las operaciones significantes que contribuyen a que San Antonio de Areco sea una opción privilegiada dentro de la pampa húmeda por argentinos y extranjeros para hacer turismo "cultural", "rural", "experiencial", "slow". Aun cuando se sustente en un desarrollo persuasivo que incluye, sin darse cuenta, en pasajes nucleares, un par de contradicciones respecto a la dimensión temporal.

Ello parece no importar, pese a que la eficacia de este "santuario" radica en obedecer el postulado que el turista (moderno) se moviliza en busca de una autenticidad que le proporciona simbólicamente una serie de atracciones que lo retrotraen con sentimentalismo a una era dorada (MacCannell, 2003). Las inconsistencias discursivas descritas, que confirman el ímpetu de la globalización, más que sumar restan, ya que solo consiguen debilitar la promesa marcaria. No representan alternativas suficientes ni seductoras para atraer por el otro flanco al post turista (Cohen, 2005). El visitante "moderno" no puede aceptar que en la tierra de los gauchos se coma sushi o se escuche jazz a la vista de todos. Así se procede a negar la fábula que tan trabajosamente se proclama defender.

\section{Referencias bibliografías}

Agamben, G. (2007): Qu'est-ce qu' un dispositif? París: Éditions Payot \& Rivales. Altamirano, C. y Sarlo, B. (1997): Ensayos argentinos. De Sarmiento a la vanguardia. Buenos Aires: Ariel. Amin, A. y Thrift, N. (2002): Cities. Reimagining the Urban. Londres: Polity Press.

Barthes, R. (1993): "Semiología y urbanismo", en Barthes, R., La aventura semiológica: 257-267. Barcelona: Paidós Comunicación.

- (1994): "El mito, hoy", en Barthes, R., Mitologías. 198-257. México: Siglo XX Editores.

Bauman, Z. (1999): "Turistas y vagamundos", en Bauman, Z., La globalización. Consecuencias humanas. 103-133. Buenos Aires: Fondo de Cultura Económica.

\footnotetext{
${ }^{34}$ La localidad cordobesa de Villa General Belgrano es otro ejemplo interesante pues actúa con enorme fuerza un dispositivo análogo al arequero que sin embargo representa el triunfo de una posición ideológica pro germánica (anti criolla). Ver Centocchi (2013).
} 
Buhalis, D. y Law, R. (2008): "Progress in information technology and tourism management: 20 years on and 10 years after the Internet-The state of eTourism research", Tourism Management, 29 (4): 609-623. http://doi.org/10.1016/j.tourman.2008.01.005

Centocchi, C. (2013): "Villa General Belgrano: La germanidad como aglutinante", La Trama de la comunicación, 17: 115-129. Disponible en web: http://www.latrama.fcpolit.unr.edu.ar/index.php/trama/article/view/421/361

Cohen, E. (2005): "Principales tendencias en el turismo contemporáneo", Política y Sociedad, 42 (1): 11-24.

Crang, M. (2003): "Placing Jane Austen, displacing England: touring between book, history and nation", en Suzanne R. Pucci y James Thompson (ed.), Jane Austen and Co.: remaking the past in contemporary culture. 111-132. New York: SUNY Press.

Earl, B. (2008): "Literary tourism. Constructions of value, celebrity and distinction", International Journal of Cultural Studies, 11 (4). Londres: Sage. https://doi.org/10.1177/1367877908096003

Genette, G. (1989): Palimpsestos. Madrid: Taurus.

Jakobson, R. (1988) Lingüística y Poética, Madrid: Cátedra.

Kavaratzis, M. (2004): "From city marketing to city branding: Towards a theoretical framework for developing city brands", Journal of Place Branding and Public Diplomacy, 1 (1): 58-73. https://doi.org/10.1057/palgrave.pb.5990005

Kim H. y Richardson, S. L. (2003): "Motion picture impacts on destination images". Annals of Tourists Research, 30 (1): 216-237. https://doi.org/10.1016/s0160-7383(02)00062-2

MacCannell, D. (2003): El turista. Una nueva teoría de la clase ociosa. Barcelona: Melusina.

Metz, Ch. (1979): "Metáfora/ metonimia: Disimetría de una simetría", en Metz, Ch., Psicoanálisis y Cine. El significante imaginario: 168-173. Barcelona. Editorial Gustavo Gilli.

Peirce, Ch. S. (1978): La ciencia de la semiótica. Buenos Aires: Nueva Visión.

Pérez Blanco, L. (2003): "Don Segundo Sombra de Ricardo Güiraldes. Reflexión en clave docente", Cuadernos para investigación de la literatura hispánica, 28: 415-428.

Pérez Winter, C. (2013): "Guacholandia'. Cuando el patrimonio entra en disputa en San Antonio de Areco", VII Jornadas Santiago Wallace de Investigación en Antropología Social. Facultad de Filosofía y Letras, UBA, Buenos Aires. Disponible en web: https://www.aacademica.org/000-063/143.pdf

Rivera Mateos, M. (2013): "El turismo experiencial como forma de turismo responsable e intercultural", Relaciones Culturales de la Diversidad: 199-217.

Semprini, A. (1995): El marketing de la marca. Una aproximación semiótica. Barcelona: Paidós.

Stewart, S. (1984): On Longing. Narratives of the miniature, the gigantic, the souvernir, the colletion. Baltimore: Johns Hopkins University Press.

Tassara, M. (2011): "Ciudades del cine", Lexia, 9-10: 233-246. http://dx.doi.org/10.4399/978885484516912

Urry, J. (2002): The Tourist Gaze. London: SAGE publications.

Verón, E. (2004): "Diccionario de lugares no comunes", en Verón, E., Fragmentos de un tejido: 39-59. Gedisa: Barcelona.

Wilensky, A. (2014): La promesa de la marca. Claves para diferenciarse en un escenario caótico. Buenos Aires: Temas.

\section{Breve CV del autor}

Claudio Fabián Centocchi es Licenciado en Ciencias de la Comunicación y Magister en Análisis del Discurso (Universidad de Buenos Aires). Integra actualmente los proyectos de investigación "Performatividad y fruición estética: apropiaciones de la ficción narrativa del cine y la literatura" (Universidad Nacional de las Artes, 2015-2017) y "Letra, imagen, sonido. Convergencias y divergencias metodológicas y teóricas en el estudio de las relaciones entre los medios y el espacio urbano" (UBACyT, 2014-2017). Es profesor en la Universidad de Buenos Aires y dirige la Especialización en Construcción de Marcas (Universidad de Ciencias Empresariales y Sociales). 